Revista Iberoamericana. Vol. LXV, Núms. 188-189, Julio-Diciembre 1999; 613-632

\title{
"UN DÍA SOLEMNE; UNA FIESTA ORIGINAL": ÁFRICA EN UN DISCURSO MUSICAL DE LA IDENTIDAD EN MATALACHÉ DE ENRIQUE LÓPEZ ALBÚJAR
}

\author{
POR \\ CAROL BEANE \\ Howard University
}

Tanto las ilustraciones para los periódicos y los libros del siglo XVIII y XIX como los cuadros de costumbres de aquellas épocas, nos proporcionan una documentación visual de la presencia de los africanolatinoamericanos. La información nos llega, ora adrede, ora inadvertidamente ya, que es posible observar "sin darse cuenta completamente de las implicaciones culturales e históricas de lo observado".' En cuanto a su música, tal documentación abarca no sólo la representación de diversos instrumentos -los tambores, los instrumentos de cuerda- sino las posiciones del cuerpo mientras se toca y hasta los movimientos del cuerpo para el baile. ${ }^{2}$ Sule Greg Wilson, en su libro The Drummer's Path: Moving the Spirits with Ritual and Traditional Drumming, describe lo que numerosos investigadores, observadores, músicos y bailadores ya han vivido: "Ponga los instrumentos europeos en manos de africanos y éstos los arreglan y los tocan según sus propias tradiciones de sonido y estilos orquestrales" (28). Mediante una relectura de Matalaché, ${ }^{3}$ novela peruana de 1928, del escritor afroperuano Enrique López Albújar, este trabajo propone indagar las posibilibidades de tal acercamiento a la africanía a nivel textual.

La acción de la novela se sitúa en la región de Piura alrededor de 1816. La esclavitud y las guerras de independencia sirven de fondo contra el cual esta narrativa de la identidad y del amor interracial se desarrolla. El protagonista de la novela es un joven esclavo mulato, José Manuel, de la hacienda La Tina. Tiene fama de ser mujeriego y de enderezar a las

\footnotetext{
' Robert Farris Thompson, African and African American Art and Philospohy (143). Sobre un modus perservandi de información y tradiciones culturales.

${ }^{2}$ Del mucho material archivado, una lista parcial: las colecciones del Centro Schomburg de la biblioteca pública de Nueva York; la Moorland-Spingarn de Howard University, Washington, D.C.; la de Hampton University, Hampton, Virginia; la Menil de Houston, Texas. Un ejemplo norteamericano de la pintura costumbrista, "JJammin' in the Quarters, The Old Plantation", ["Jornada musical de improvisaciones en el barrancón, La vieja plantación”] de mediados del 1700 en la colección de Abby Aldrich Rockefeller, Williamsburg, Virgnia. Unos ejemplos de ilustraciones del siglo XIX son las preparadas por Johan Moritz Rugendas y Jean-Baptiste Debret del Brasil; las de Robert C. Markham del Peru, History of Peru, Chicago, Charles H. Sergel and Co.,1892; las hojas de música pautada ilustradas, de 1883, "Camptown Races", muestra la posición indicada para tocar cierto tipo de tambor en Sule Greg Wilson, The Drummer's Path; Moving the Spirits with Ritual and Traditional Drumming (23). Todas las traducciones del inglés al español son mías a menos que se indique lo contrario.

${ }^{3}$ Enrique López Albújar, Matalaché; una novela retaguardista. Todas las citas son de esta edición.
} 
esclavas, costumbre a la cual en la novela se refiere como un "yogamiento forzado" con el fin de que ellas quedaran preñadas (166). Se enamora de María Luz, la hija del hacendado y logran consumir a sus amores furtivos. Mientras la reputación de José Manuel para satisfacer a las esclavas negras inspiraba envidia en los amos blancos, su relación con María Luz infundía envidia en los esclavos negros. Finalmente, el secreto se revela y a los enamorados les es menester enfrentar las consecuencias de su pasión atrevida.

Lo singular del texto de López Albújar, sobre todo para su época, es que para contradecir los retratos despectivos que la clase esclavista hacía del mulato, llamándole en diversas ocasiones "garañon", "fiera", "tiburón", y "ogre" enfatizando así la bestialidad de su condición de esclavo el autor no recurre a las estrategias europeas como ser alfabetizado o letrado como a las pruebas únicas de valor humano y social. ${ }^{4}$ A pesar de que José Manuel sí es alfabeto, el autor prefiere explorar otro proceso de valorización del individuo, uno que se basa en y se aferra a ciertas tradiciones africanas, específicamente la payada, evento musical. Lo hace no sólo por medios verbales, los cuales no prevalecen, sino por medios aún más abarcadores y afectivos — su creación de la vida a través de la experiencia totalizadora y sensorial de la música. Como la música — subversiva, exigente de una autonomía cultural, de la diferencia - de esta escena que presenta López Albújar al lector, José Manuel cumple con el papel de músico según la definición de Jacques Attali: “[...] a la vez musicus y cantor, reproductor y profeta. Brujo y médico, canalizador de la violencia. Quien habla de y contra la sociedad" (12). Sin equívoco, el autor se plantea la paridad de estas valorizaciones para con lo europeo, en cuanto a poder confirmar la humanidad del individuo.

Por una parte, López Albújar se aprovecha de un discurso de enajenamiento y diferencia para hacer hablar a la clase esclavista de su relación con los negros y mulatos. Ya se mencionaron los atributos negativos que caían sobre el mulato. En la novela el apodo suyo, "Matalaché", de uso común entre los negros esclavos y los amos blancos, por las conotaciones sexuales, es alusión clara a una naturaleza lasciva. López Albújar, en cambio, aprovecha de la diferencia en cuanto a expresión cultural para construir para su protagonista un discurso de afirmación. Este discurso funcionaba como un reflejo de la interioridad del protagonista y servía para desbaratar los estereotipos del mulato vicioso y violento y el del mulato trágico, impedido de actuar o obrar por su neurosis de inferioridad y por el odio hacia sí mismo.

La payada es el vehículo principal escogido por López Albújar para la declaración más completa y profunda de la identidad de su protagonista. Aunque popularmente asociada con la Argentina, la payada es un discurso musical de forma casi netamente africana; se describe como un duelo entre dos guitarristas, organizado alrededor de un contrapunteo improvisado de música y voces o bien sobre un tema dado o como repuesta a los retos que allí se lanzan. Se considera "una variación vocal de las tapadas, las competencias de tambores, y así un descendiente directo de la tradición africana de las competencias musicales, tradición que

\footnotetext{
${ }^{4}$ La importancia de ser letrado en la tradición norteamericana de literatura de la esclavitud, cuyo ejemplo máximo es "La narrativa de la vida de Frederick Douglass", en The Classic Slave Narratives, ed. Henry Louis Gates, Jr.; Robert J. Steptoe, From Behind the Veil: A Study of Afro-American Narrative, un análisis de la literatura afronorteamericana enfocado en la alfabetización y el proceso educativo.
} 
ha producido fenómenos parecidos en todos los países americanos donde se encuentre una población considerable de descendientes de africanos" (Andrews 170).

Al payador, actor de este drama social en el cual hay tantas manifestaciones del poder, el pensador argentino Domingo F. Sarmiento, en Facundo. Civilización y barbarie (1845) lo caracteriza, entre otras cosas, como alguien que se mueve en las fronteras límbicas, "entre la vida que se va y la que se acerca" (245). Volveremos sobre estos puntos al proponer ciertas intenciones para la payada como recurso literario ya que parece encerrar un significado polivalente. ${ }^{5}$ Puesto que en esta novela existe una polivalencia en cuanto a la interpretación de los personajes, bien se puede pensar que el texto encierra otras claves o signos que llamarían la atención de un lector, un oyente, o un crítico que percibiera en ellos aún más significados basados en las culturas de Africa del oeste.

La payada, compuesta de elementos africanos y europeos, contextualizada en una de las fiestas mayores de la Iglesia católica, como se presenta y es utilizada por López Albújar en el capítulo XIV de su novela, también es una forma de drama social con sus propias consecuencias, como se verá. Victor Turner explica cómo "el drama social como paradigma va de lo cognitivo a lo existencial y en el proceso se viste de alusiones, implicaciones y metáforas" (73). Esto se conforma a la manera en que se desarrolla la payada. Así se permite la introducción de una serie de expresiones y creencias formadas en unas de las culturas africanas. Me refiero a las varias manifestaciones del poder, o ashé (palabra yoruba), el espíritu, que es un elemento imprescindible para nuestra discusión de la actuación y el drama de la payada. El ashé se puede manifiestar por los ojos que sirven de ventanas al alma según las convenciones occidentales y las metáforas literarias; es de notarse la orientación interior. Mas según ciertas creencias de Africa del oeste, la metáfora de la ventana sirve para conducir el poder interior desde adentro hacia afuera; así, los ojos saltados simbolizan esta visitación del poder, del ashé al individuo. Desde luego los ojos y la fuerza de la mirada —ora seductora, ora manipuladora - son elementos integrados en la caracterización del protagonista, el mulato José Manuel. El mulato se impone en la payada con su "mirada zahorí" y su consciencia y dominio de la situación, a pesar de que el evento se haya iniciado por los amos. Con la vista se muestra capaz de manipular los desquilibrios, las sutilezas y las inversiones de papeles que aquella payada se le presenta (171). Sus ojos son calificados de "ofídicos"; otro detalle cuya vigencia cabe tanto en un sistema europeo - la tentación, el mal- como en un sistema africano - un tótem poderoso, asociado con Dambala, ente omnisciente de la tradición dahomeana, el que sana, que pone orden, que da inspiración (Thompson 176).

Para entender mejor la formulación de la identidad racial y cultural en esta novela que se ofrece en este trabajo, conviene examinar la relación entre la demografía y ciertas

\footnotetext{
${ }^{5}$ Para una discusión sobre la polivalencia del Matalaché de López Albújar, véase en el libro de Tomás G. Escajadillo, La narrativa de López Albújar (Lima: Ediciones CONUP, 1972), su capítulo, "Análisis de Matalaché. Para leer a Matalaché: el mundo polivalente de una novela retaguardista". Las páginas 291 y siguientes se enfocan en el duelo musical de los dos cumaneros. Ver también el comentario, Notes for the Loango Tusk [Apuntes sobre el colmillo de Loango], de Andrea Nicholls, Assistant Curator of American and African Art (Washington, DC: The Smithsonian, 1997) en el cual se cita a Wyatt MacCaffey, Astonishment and Power (The Smithsonian, 1996) 31. MacCaffey sugiere que en el contexto africano durante la época de la esclavitud la transmisión de cierta información se lograba por poderse aprovechar de diversos niveles de comprensión y sistemas de signos y claves.
} 
expresiones culturales afroperuanas. La geografía nos provee ciertos puntos de referencia en cuanto a Matalaché, mientras la demografía y las actitudes resultantes de ella son claves para cualquier discusión sobre la identidad en el Perú del siglo XIX, como en gran parte sigue siendo el caso hoy en día. En particular, nos interesan las actitudes y actividades que estuvieron en vigencia a lo largo de los últimos años de la época colonial y los primeros de la joven república, hasta entrado el siglo XX. Serían las que López Albújar al escribir Matalaché en 1927 habría tenido muy en mente.

La presencia de los africanos en el Perú durante la época colonial se ha documentado bien por las investigaciones de Frederick Bowser, Rolando Mellafe y otros. ${ }^{6}$ En Matalaché se mencionan varias regiones -Piura, Lambeyeque - que el lector que desconozca a fondo de la tierra y la historia peruana luego de investigar descubre que son lugares donde ha habido una fuerte presencia africana desde la época colonial y que esto continuaba a lo largo del periodo posterior a la independencia. El texto de López Albújar identifica la esclavitud con la región de Piura; mas el lector tendría que o bien saber o bien deducir tal conexión para los otros lugares nombrados. Las autoridades concuerdan que la dependencia de la costa de la esclavitud se desarrolló desde una época temprana y se arraigó en la región; una situación, según Peter Blanchard, comparable con la de Cuba y Brasil (xvii). Incluso se sabe que el abastecimiento jamás cumplió con las demandas ni las del litoral ni de Lima, de modo tal que el contrabando tempranamente se convirtió en la manera principal de conseguir esclavos. Después de 1650, el tráfico de carne humana se hizo aún más indirecto (Bowser ix).

Blanchard describe la población de esclavos en vísperas de la independencia en el Perú como "[...] no grande [...] concentrada por la costas [...] en las rías estrechas que se encontraban entre Piura en el norte e Ica al sur, con el grupo más grande en Lima" (14). Al escribir acerca de la situación en el Perú, entre 1799-1810, justo antes de la abolición de la trata por Fernando VII para las colonias en 1817, Blanchard nos informa que durante este periodo se importaban esclavos hasta de Buenos Aires y de Chile (4). El que hubiera peruanos, hombres de negocios, con su sede de operaciones en La Habana, Cuba, también nos proporciona información en cuanto a una fuente de esclavos que vinieran entrando en el Perú (50).

El historiador también documenta los casos del siglo XIX de trabajo temporal en los cañaverales en época de la zafra, cuando los que habían venido de la región andina trabajaban hombro con hombro con negros libertos o manumisos, o bien, con esclavos. Esto indica un contacto entre la sierra y la costa y entre la población africana y la indígena mayor de lo que generalmente se ha reconocido. Un periódico limeño (1845) declaró que los obreros libres como éstos era los responsables por el cultivo de la caña y la produccón del azúcar por los districtos de Lambeyeque y Camarrará (Blanchard 23).

Otro elemento de mayor mobilidad y contacto entre las tres culturas en la época colonial habrían sido los muleteros, que según toda información, eran negros (Blanchard

' Frederick P. Bowser, The African Slave in Colonial Peru; 1524 -1650; Rolando Mellafe, Negro Slavery in Latin America; James Lockhart, Spanish Peru, 1532 - 1560: A Colonial Society. Ver también David C. Chandler, "Slave Trade of New Granada", en Slavery and Race Relations in Latin America. Al comentar las rutas del tráfico entre Nueva Granada y Lima se menciona un tráfico de contrabando que existía por la región costera del Perú que abarca Piura. También Peter Blanchard, Slavery and Abolition in Early Republican Peru. 
2). ${ }^{7}$ A pesar de poner énfasis sobre las funciones económicas de los esclavos, es imprescindible considerar el aporte cultural de ellos también y las formas que éste tomara. Los ejemplos de proveniencia y su distribución en el Perú postulan una interacción más extensa entre los esclavos de diversos lugares, la cual seguiría a lo largo del siglo XIX. El que hubiera contacto, por ejemplo, entre la población afroperuana con los africanos venidos al Perú via Cuba, cuando no con los esclavos negros criollos cubanos, aumenta la posibilidad de expresiones culturales semejantes, sobre todo en cuanto a la música y el baile.

Dado que uno de los aspectos más destacados de la vida del esclavo era su resistencia a la esclavitud, quisiera examinar la manera en que ciertas formas de resistencia perduraron, afectando "a" y afectadas "por" aquel movimiento complejo de personas. Me refiero no sólo al cimarronaje sino a la preservacion de ritmos, bailes, música y los estilos de tocar ésta. También es de considerar de qué modo un autor pudiera aprovecharse de esto al crear un personaje, una construcción imaginativa — situada en un determinado periodo histórico. Dada la persistencia de las actitudes negativas en cuanto a los negros y a los mulatos que prevalecían en la sociedad peruana del siglo XIX, y las medidas oficiales que se ejercieron para impedir cualquier cambio que mitigara la condición de los esclavos o amenazara a la esclavitud como institución (Blanchard 11) se ha de esperar por parte de los afroperuanos un desarrollo concomitante de estrategias de resistencia a la aniquilación cultural y de signos para señalar esa resistencia.

Bowser describe como "la iglesia católica recurrió a la música para atraer a los africanos y fomentaba su asimiliación al regimen colonial por promover su devoción a un santo o santa particular"'(246). Las primeras cofradías se fundaron en 1540; principalmente era el élite de los esclavos la que participaba (Bowser 250). Bastante documentación existe que comprueba las sospechas constantes por parte de las autoridades coloniales, que veían en las cofradías una fuente de costumbres paganas y supersticiones para los afroperuanos (Bowser 251). Cabe señalar que lo que aquí se le llama "superstición" bien puede ser otro sistema de creencias filosóficas, el cual si basado en las africanas, se habría descartado en aquella época.

Al discutir la supervivencia de los patrones de la cultura africana en general, Bowser especula que "[l]os conocimientos de las tradiciones eran posiblemente el santo y seña para ganar entrada en un lugar desconocido" (174). ${ }^{8}$ La gente de la diáspora habría elaborado no sólo sistemas de encerrar tales conocimientos e información sino que también más de un modus operandi. Blanchard señala las cofradías como "ejemplo del fracaso de las autoridades coloniales de erradicar la herencia africana de los esclavos. Las celebraciones religiosas, por el uso de la música, el baile y los espectáculos, ofrecieron la posibilidad de adoptar y transformar ciertos elementos culturales y de transferir otros africanos. Había las

\footnotetext{
${ }^{7}$ Véase la ya citada obra de Robert Clement Markham, $A$ History of Peru; del siglo 18, véase $E l$ Lazarillo de los ciegos caminantes escrito por Calixto Carlos Bustamante, llamado Concolorcorvo. ${ }^{8}$ Los estudiosos de otras disciplinas - la música, el baile, los tejidos- han venido descubriendo pruebas de otros sistemas que los esclavos desarrollaron y utilizaron para trapasar información para sobrevivir. En el llamado"Underground Railroad", refiriéndose a las rutas clandestinas de escape del sur al norte en los Estados Unidos, por ejemplo, se sabe que la manera de colgar un colcha para secar, y hasta los diseños de la colcha servían para proteger y orientar a los que huían. Ver, por ejemplo, el estudio que está por publicarse de Raymond G. Dobard y Jacqueline L. Tobin, Hidden in PlainView: The Secret Story of Quilts and the Underground Rail Road.
} 
cofradías patrocinadas y promovidas por la iglesia, que surgieron entre la población negra en el Perú; había además cofradías independientes como la de los Congos Mondongos que claramente quisieron mantener o fomentar los lazos africanos" (2).

Blanchard discute el propósito y el efecto de las celebraciones organizadas por las cofradías. Aunque "algunas cofradías aceptaron socios sólo de una nación particular, con la posibilidad obvia de ser agencia de transmisión cultural, mientras sus celebraciones, no obstante los requisitos de ser socio, alcanzaron un público aún más amplio" (2). Se puede suponer que hasta en la época colonial tardía, y más allá, cuando las cofradías se hacían menos exclusivas en cuanto a etnia, el próposito, y muchas de las convenciones de sus celebraciones perdurarían a pesar de todo.

Estudiar las cofradías es también interogarse acerca de las cuestiones del control y de la subversión, y la potencia de la confrontación. Por su parte, las autoridades coloniales veían en las actividades de las cofradías una forma de control social no coercitivo para su población afroperuana. Se permitió a los esclavos reunirse en grupos numerosos y expresarse mediante la música de tambor y bailes - actividades que en otras circunstancias hubieran dado miedo a los dirigentes de la sociedad esclavista. La falta de coerción facilitaba el juego entre las intenciones y los propósitos de ambos grupos y se prestaba a la co-optación y la subversión. Cuando, por ejemplo, las cofradías negras adoptaron a Santa Bárbara como su santo patrón de sus devociones y la unieron con su propio orixá o divinidad yoruba, Shangó, lograron que la regalia de la santa coincidiera con los colores - rojo y blanco- de Shangó Murphy 30). Así un sistema que se asocia con los pueblos de la diáspora, informado tal sistema por una consciencia de símbolos culturales polivalentes que hasta cierta punto coexisten y una habilidad de manipularlos. Sea representar las actividades de las confradías por lo visual, lo auditivo, o lo kinético (el baile), la información contenida en tal sistema estaría a la disposición sólo de quienes supieran qué señales buscar.

La situación social más flexible (algunos la calificarían de "humana") del africano en el Perú facilitó la retención de una "autonomía cultural"para construir una vida y cultura no del todo controlada por la clase dominante" (Scott, citado en Blanchart 64). La resistencia fundamental a la esclavitud apareció en forma del ejercicio de las tradiciones y costumbres africanas (Blanchard 97). A pesar de que no ofreciera un desafío abierto a la esclavitud, sí permitía que se mantuviera la herencia racial africana, mientras que, el mismo tiempo "confirmó la diferencia con la población local, y ofendió profundamente al grupo dominante" (Blanchard 99), creando así una ansiedad omnipresente e insidiosa de represalias y venganzas entre los blancos esclavistas, ansiedad que se intensificó después de la independencia de Haití.

Desafiar al grupo dominante se percibía siempre como amenaza, lo cual constituía la acusación más seria contra el grupo subyugado. Por ella se explica el conservadurismo del Perú en vísperas de la independencia: el apoyo general que continuaba para la Corona española; la insistencia en mantener la trata; la aversión a implementar los provisos de la abolición; la negación a la población afroperuana de sus derechos civiles y sus beneficios militares; la circunvención de todo proceso de liberación. Hasta Bolívar, el Liberador, expresó sus cavilaciones en cuanto a la posibildad de una pardocracia en Venezuela, acabada la lucha por la independencia. ${ }^{9}$

\footnotetext{
${ }^{9}$ Carta de Simón Bolívar a su hermana citada en Magnus Mörner, Race Mixture In Latin America.
} 
Este mismo sentimiento negativo aparece en boca de uno de los personajes en las primeras páginas de Matalaché, enlazando así la novela con todo ese planteamiento. También se relaciona aquella discusión con las formas que emplea López Albújar para desarrollar el cáracter de su protagonista y las ideas sobre la identidad formadas en los varios discursos de otredad y diferencia que sirven de base para los miedos políticos y las ansiedades culturales, además del imperativo de hacer valerse de la cultura de uno. El temor profundo a "las inquietudes sociales" que la sociedad colonial llevó hasta la época de la independencia, es indicio de una ansiedad violenta, el subtexto del sistema de las plantaciones (Blanchard 5). Es precisamente esta ansiedad la que explota López Albújar al darle forma a la identidad de José Manuel y que la payada desafía y deshace.

Al referirse tanto a las formas de resistencia abiertas como a las subversivas, Blanchard dice, que "provocaron ansiedades entre los blancosy paulatinamente se fueron convenciendo a cada vez más peruanos que [la esclavitud] era un inhumano anacronismo sin justificación que no tenía lugaren su país"(Blanchard 97). ${ }^{10}$ La ansiedad condujo al cambio. Examinemos ahora algunos de los detalles específicos que se han documentado en cuanto a la práctica de costumbres africanas como forma de resistencia y el modo en que se coincidía con el mandato del gobierno colonial para mantener el orden y el control. Tengamos en cuenta el papel del espectáculo como indicio del control, función que cumple la payada literaria presentada por López Albújar. También, precisa reconocer que lo que para ciertas autoridades representaba el control, para los individuos involucrados en el espectáculo los participantes activos - el espectáculo ofrecía un espacio y hasta una estructura que se prestaban a una subversión de ese mismo control. Así es, sobre todo tratándose de una relación antagonística como la presente en la novela entre los esclavistas -el público-y las personas esclavizadas - los músicos y participantes.

Bowser nos informa que en 1549 hubo varias protestas causadas por las cofradías. Se les acusaba de tener "el escándalo" por su actividad principal (Blanchard 246). Se refiere a festivales que "tenían un sabor africano diferente, creado principalmente por la música que los acompañaba en la cual el cajón de madera o tambores de origen africano, y tocados casi exclusivamente por negros, tocaron ritmos para sus bailes [...]." En relación con estos festivales se menciona también la ubicuidad de "las máscaras, los diablos, y los gigantes, éstos basados en modelos africanos, vestidos en disfraces elaborados, por encima una máscara, bailados con cacofonía de arpas, guitarras, violines y otros instrumentos para hacer ruidos [...]" (Blanchard 99). " Comenta que "[...] restos culturales tales como éstos sobrevivieron en los barracones de la hacienda y en los barrios negros de las ciudades" (Blanchard 2).

El escándalo bien puede entenderse como sinónimo de la cacofonía. Se ha visto como la cacofonía, junto con la música, y el baile son elementos claves del espectáculo en un

\footnotetext{
${ }^{10} \mathrm{La}$ alternativa preferida era reemplazar la población no blanca/no europea con imigrantes europeos blancos, según el patrón en vigencia por aquellos años en los Estados Unidos, la Argentina, y Venezuela entre otros.

"La persistencia de estos elementos en los festivales de la diáspora confirma su importancia. Se puede añadir a los ya conocidos carnavales de antes de Cuaresma y al Día de Reyes, los días de Pinkster y Quasimodo, celebrados en el estado y la ciudad de Nueva York y Lima del siglo 18 y 19 con disfraces y gran cacofonía de arpas, guitarras, violines y otros instrumentos para hacer ruido (Wilson 21; Blanchard 99).
} 
contexto de rito y festejo. En la payada de Matalaché, tan informada por la africanía, ésos son los elementos que significan la autoridad y la identidad. La fuerza del ruido se encuentra en su disconcordancia, en su capacidad de inquietar y trastornar, lo cual puede ocurrir aún más cuando existan diferencias culturales y estéticas entre los participantes y el público que los observa. Fernando Ortiz declara que en muchas culturas africanas existe una estética bien diferenciada de la europea en cuanto al ruido. En ellas el propósito de la cacofonía es de atraer y no de ahuyentar (348).

Son de interés aquí también las discusiones de Jacques Attali. Crear ruido puede entenderse como una amenaza de la muerte (27). Implica la autoridad —así que en parte el término, "cacafonía", para describir las procesiones de las cofradías implícitamente reconoce este atributo de descomponer el order. De allí la ansiedad provocadora por parte de los amos de esclavos. Al mismo tiempo, si se acepta la música que crea José Manuel en la ocasión de la payada, aunque por mandato del amo, se ve que cumple con esta función tal como la plantea Attali. Mas a la vez la música de José Manuel transciende la ocasión de espectáculo religioso porque en ella se encierra una clave, una profunda invocación en clave al espíritu, al ashé del individuo y del pueblo esclavizado.

En cuanto a la estructura de la payada se inicia con la presentación de los dos músicosduelistas: en la novela, José Manuel y el negro Nicanor, y el reto que se lanzan. Según la tradición oral hay una invocación a guisa de preludio a las improvisaciones que siguen a continuación con las respuestas musicales y los contrapunteos. Attali explica que "primordialmente la producción de la música tiene por su deber la creación, la legitimización y el mantenimiento del orden. Su función principal no se ha de buscar en las estéticas sino en la eficacia de su participación como factor en la regulación social" (30). El mismo crítico refiere al flujo de información [que] puede crear un nuevo orden" (32). Tanto la invocación como el resto de la payada de López Albújar nos proporciona música, sensaciones y reacciones nuevas.

Veamos el papel del conjuro y la invocación en la payada de Matalaché. Del conjuro Ortiz explica que es la palabra de los seres que no hablan en la cual incorpora así su propio valor expresivo la locución humana que formula el conjuro (Africania 341). En Matalaché, los personajes esclavizados carecen de voz. Bien para defenderse, bien para reclamar y afirmarse, José Manuel, a través de sus creaciones musicales, procura atraer a las potencias a que le concedan la voz o lo animen a la búsqueda y al empleo de su propia voz.

Hay también una invocación al instrumento. Ortiz menciona como "la guitarra en algunas circunstancias [es] capacitada como los tambores para el "habla...". (Africanía 325) y del "habla" observa que el movimiento oratórico de ciertas palabras (¿encantamientos?) se traduce en percusión del tambor. Se habla también de hacer hablar el tambor -en este caso, la guitarra - y se dice que sólo un iniciado puede hacerlo (Notal 162). A propósito de esto, si se lee detenidamente la reacción del negro Nicanor después de escuchar a José Manuel tocarle el reto/invocación, se percibe su fascinación con la música del mulato. Nicanor se pregunta "de dónde aquel tocador maravilloso", y "de dónde había sacado este hombre tanta fuerza y maestría para dominar así un instrumento tan rebelde..." (López Albújar 174). Al responder a esta pregunta retórica, recordemos el traje y el porte de José Manuel, sobre todo aquel jubón de piel de tigre, tan comentado por las mujeres blancas presentes. Ellas le atribuían poderes eróticos, mas en el contexto de la africanía pudiera 
señalar su estado de iniciado en alguna sociedad secreta, con cargas especiales. Por ejemplo, Robert Farris Thompson describe el papel del leopardo real, en la novela criollizado al tigre, como guardián y protector del estado (86). Se le conduce al lector a pensar en sus propiedades e implicaciones totémicas, de camuflage, de transformaciones, de bailadores disfrazados de cazadores quienes son devotos a Ogún, orishá o divinidad yoruba de la construcción y la destrucción, cuyo elemento es el metal; cuyos movimientos y acciones se caracterizan por lo repentino, lo decisivo, lo violento (Thompson 52). En cambio la dignidad y la autoridad del mulato son reforzadas por su comportamiento intenso y controlado durante la payada. Por las posibilidades de este tipo se encuentra una justificación mayor por insistir en ciertas asociaciones entre José Manuel, su aparencia durante la payada y el don de su música.

Según Ortiz, "en la música más quizás que en otra parte, intervienen de manera inextricable infinidad de factores objetivos y subjectivos, sensoriales y elementales, naturales y convencionales, emocionales e ideológicos, individuales y sociales" (Ortiz, Africania 353). La música en la cultura africana se considera sagrada, una "invocación a las energías vitales que aseguran la sobrevivencia de una comunidad" (Wilson xiii). La música aporta el poder, la autoridad y la identidad. La payada viene a señalar una acumulación de potencias invocadas que también invocan.

Se representan "las energías vitales" en el caso de José Manuel esencialmente por la energía sexual. Esta constituye la imagen del mulato propagada por los esclavistas -un monstruo de la sexualidad, cuyos excesos conducen a la violencia y la destrucción. "Las energías vitales" por otra parte, representadas en la payada contradicen este estereotipo, y lo que es más, como venimos comentando, en las manifestaciones de estas energías predominan las resonancias no-europeas. Sule Greg Wilson describe al músico como alguien que "manipula el poder en forma de sonidos que afectan el genio de uno, de información encerrada en formas icónicas" (Wilson xvi).

La energía a la cual se alude aquí es el poder fundamental que reside en el músico. Es la base de su creatividad concebida en dos aspectos lo biológico y lo político. Tal como se representa en la novela, el propósito del músico es invocar el espíritu o la voz del instrumento - la música, es el vehículo para la comunicación (Wilson 98). En su definición del acto de salmodiar, el músico-escritor Wilson lo compara con el proceso de invocación que es "un arreglo musical de notas que estimula y ponen en accción ciertas funciones del cerebro, y cuya poesía lírica invoca imágenes que refuerzan y estimulan los estados alterados de consciencia inducidas por los efectos de la melodía y el ritmo[...]" (Wilson 98).

En la primera parte de la payada cuando José Manuel toca, hay un énfasis no sólo en la manera de tocar sino también en el efecto que ejerce sobre los oyentes:

[...] comenzó en pianísmo un preludio sollozante [...] como un leve rumor de alas [...] en intermitencias sutiles y frágiles, llegaba un fluido melódico y penetrante, que iba envolviendo a las almas en visble arrobamiento. Y lentamente la suave melodía fue creciendo y elastizando hasta convertirse en furiosa tempestad. Una mezcla de gemidos y sollozos extraña, como de mujeres agónicas y hombres atormentados, brotaba del hexacorde instrumento en cascada ruidosa, violenta, que al terminar, hizo levantarse al público y aplaudir con frenesí (171). 
Esta música está llena de alusiones y evocaciones. Frases como "mujeres agónicas y hombres atormentados" y la calificación de la música como "flor de galpón" provocan una meditación sobre la esclavitud. Los aplausos emocionados de su público son los primeros pasos de una ceremonia cuya organización será dictada por el músico José Manuel, sépalo o no la elite de la sociedad piurana. Así fue durante el primer momento de la payada.

En el segundo momento se entra de lleno en la contienda. El orden en que José Manuel toca las piezas sugiere una jerarquía de afinidades y valores estéticas en el texto. También muestra sus conocimientos de las vías históricas y económicas que servían de puntos de contacto cultural. Al examinar el inventorio de las ofrendas musicales que sirven de fundamento para la identidad cultural de José Manuel, se ve que se incluye bastante música polirítmica y de ritmos sincopados que nos acerca a una estética africana, aunque sus manifestaciones sean algo criollizadas. Comienza con la música cubana y parte de ahí hacia lo desconocido y lo nuevo. Se describe la intensificación del efecto de la música de José Manuel: "un nuevo preludio impúsoles silencio a todos, y de la guitarra de José Manuel principió a brotar un raudal de cristalina armonía, más exquisito y arrobador, si cabe, que el primero [...]" (López Albújar 194). Vale reproducir a continuación la cita completa en la cual se describe la trayectoria musical del mulato:

\begin{abstract}
Y al preludio siguieron unas danzas de sabor exótico, voluptuosas, ardientes, como la tierra de donde provenían. Era música cubana: la habanera, el singumbelo, la guajira, todo un repertorio nuevo, aprendido por José Manuel en sus viajes a Paita, en las posadas de los marineros, o a bordo de los navíos venidos del mar Caribe, o en sus viajes costaneros, que iban a rematar en el Callao. Y luego la emprendió con la música de la tierra, con los tonderos morropanos, de fugas excitantes, los mangacherinos, tanagareños y lambayecanos; con toda esa música ajimordente y revoloteadora, flor de galpón, deletérea, opiante, con pretensiones de poesía picaresca, improvisada por la musa popular, como la resbalosa, el agua de nieve, la moza mala, la mariposa, el tondero, el pasillo y el danzón. [...] Después pasó a la música sentimental: la serenata, el triste, la canción, rematando con una danza nunca oída hasta entonces, epiléptica, lujuriosa, azuzadora, cancanesca, descoyuntante y pegagosa, toda llena de fugas y contrapuntos, y tan comunicativa, que contagió su epilepsia al auditorio. Aquello era un nuevo son de los diablos, tal vez la invención de Matalaché, melódico, clarinesco, original, sin ese tamborileo bárbaro, carraquiento, estúpido del son de los diablos limeños (175-176).
\end{abstract}

Es notable la fuerte representación de sus bailes o sus ritmos, a pesar de las calificaciones negativas que acompañan a algunos de ellos. Se puede interpretar por un lado, como una exploración del autor del querer deshacerse de cualquier conexión con lo africano. ${ }^{12}$ Por otra parte cabe señalar que se conserva la estructura de los ritmos/bailes aunque se habla de modificar la expresión. La relación obvia entre el baile y el ritmo es otro mecanismo que sirve para guardar los elementos culturales. Se ha dicho que en las culturas

\footnotetext{
${ }^{12}$ Hay varios ejemplos de una actitud ambigua en cuanto a lo afro/lo negro en la novela. El ejemplo principal es la escena de auto-reflexión que hace José Manuel de joven en la biblioteca de la casa grande, en la cual él se repugna de lo que percibe en sus propias facciones como características africanas. También justo antes de la payada, María Luz sueña con José Manuel, transformándolo en hombre elegante, blanco y de su propia clase social.
} 
donde mucho se ha perdido (de los elementos culturales) los movimientos del baile hasta reproducen kinéticamente las descripciones verbales perdidas por los motivos que fueran. Como escribe M. T. Drewal en una consideración del baile y los orishás, "[S]i las recitaciones orales que poseen ashé invocan a los poderes sobrenaturales, les dan vida, los ponen en movimiento, entonces el baile representa de forma más literal, la materialización de estos poderes en el mundo" (203). [...] Para ella, "[N]o hay en ninguna parte que esta relación entre las palabras y las acciones sea más explícita que en los esfuerzos verbales y quinéticos que se asocian con la deidad Ogún [...]" (228). Según nuestra interpretación de la payada, existen tales manifestaciones claramente, sobre todo en la última parte de la payada.

El tercer momento de la payada es el del mayor contrapunteo, de tema libre. Nicanor, según nos dice el texto, hizo lo que pudo: "Apenas si se atrevió a improvisar e invectivar a José Manuel en verso..." (176-177). El brío con que responde José Manuel a la música de Nicanor es consistente con las observaciones sobre su modo de tocar la señal de emoción intensa, de un espíritu encendido pero a la vez, controlado, conforme con el concepto de "itutu" - la concentración espiritual, cargada con ideas de la belleza y el decoro, la pasión encauzada, asociada con el color azul (Thompson 11). El itutu o el "cool", tan valorizado en la estética yoruba, y en la de la diáspora africana, de tan difícil traducción a otros idiomas por las múltiples sutilezas que carga y engendra, del cual el negro Nicanor carece. A medida que va desarrollándose la payada se nota cada vez más la falta en Nicanor de este atributo ya que "[...] cada estrofilla suya era al punto contestada y rebatida en forma abrumadora por su contendor, quien, implacable, lo confundía, lo estrechaba y lo tundía hasta hacerlo a ratos enmudecer" (177).

$\mathrm{Al}$ examinar la actuación de José Manuel en la última fase de la payada, se nota que predomina una música sin letra. De la música instrumental en el contexto de la africanía, Ortíz observa que "sirve para fortificar la magia, para cargarla de más maña, y en definitiva para hacer que el rito sea ostensible y colectivo, en vez de esconder bajo su contrasonora el misterio, el conjuro" (Africanía 341). La pieza de remate tocada por José Manuel se aprecia como algo completamente original, "una danza nunca oída hasta entonces [...] toda llena de fugas y contrapuntos[...]" (195). El que José Manuel ya hubiera conjurado los danzones, diablitos, tangos - bailes esencialmente africanos - evoca una red compleja de alusiones y referencias culturales para quienes estuvieran enterados. Algo de exótico tendrían los bailes, pero, más para los espectadores blancos. Hay que fijarse en que la forma de la presentación de la payada en la novela de López Albújar sugiere una comprensión no superficial de diversos elementos de la africanía tal como se muestra la reacción de los espectadores negros, quienes fueron complacidos y no se manifiestaron sorprendidos en absoluto, ni por la excelencia y ni por la expresión de la energía creativa que José Manuel manifiestaba.

Frederick James, en su prefacio al libro ya citado de Jacques Attali, escribe de la problemática en la cual se manifiesta "el sentido de que algo nuevo está surgiendo alrededor de nosotros, un nuevo orden económico en el cual las nuevas formas de relaciones sociales se puede ver en los intersticios del viejo orden del cual nuevas formas de producción cultural pueden darnos el síntoma más precioso, si no la anunciación profética" (Attali xii). Hay que tomar en cuenta esta dinámica al discutir la payada. Será a través del papel de la música, 
los efectos de la música y del ruido que se logra percibir "lo nuevo" como elemento clave de la payada.

Al revisar las dos tradiciones musicales representadas en este episodio -la africana y la europea - se percibe cierta convergencia de ideas en cuanto a la expresión musical y su aporte como recurso literario. Attali, al comentar el proceso de escuchar, dice que "con la música nace el poder y su contrario la subversión" (Attali 6). Continúa diciendo que "la voz subversiva [de la música] indica una demanda para la autonomía cultural, el apoyo para la diferencia o la marginalidad"'(Attali 7). Este planteamiento cuadra con las circunstancias de la payada, episodio emblemático, de López Albújar.

En cuanto a la representación de la música que crea José Manuel, de un lado el autor retrata a José Manuel como el mulato trágico, figura romántica. ${ }^{13}$ Hace que obre y actue dentro de un discurso de enajenamiento que — según se sugiere - facilitaba su aislamiento. Como músico dentro del contexto de las tradiciones europeas y africanas, la música de José Manuel - los romances, las canciones de amor no correspondido, y otras lamentaciones sobre su destino - declaró de forma íntima la soledad y la individualidad del hombre, tanto como la impotencia que sentía frente al hecho de verse esclavizado. Por otro lado, se puede decir que al llegar José Manuel a la payada revestido de las imágenes violentas y hasta monstruosas promulgadas por los amos de esclavos, esto, en términos de la música equivaldría a la cacofonía, con las connotaciones negativas en relación a lo europeo. Había una percepción vigente con respecto a la música africana que la calificaba de bárbara en aquel entonces, y una reacción de menosprecio en cuanto a la participación de la población afroperuana en los carnavales y otros festivales (Nodal 158 -159). Para la elite de la sociedad piurana de la novela, era imposible concebir que tal energía asociada con José Manuel en la persona de Matalaché, conduciría a una música armoniosa y original. Según Attali, la armonía en el siglo XIX hizo creer a la gente en la legitimidad del orden social en vigencia (61). La música de José Manuel desafíaba al orden establecido y más aún, proponía otro mundo con otras estructuras y orden. Attali habla también de la consciencia de los músicos de su posición en el mundo, y cómo, al representarla de una forma romántica "el individualismo exacerbado condujo a una ruptura en el proceso de la representación; los músicos se vieron conducidos hacia una conciencia cada vez más clara de sus relaciones con el mundo y las divergencias entre la creación y la realidad; obraban en un mundo, en una realidad ajena a sus visiones" (Attali 81). Esto describe las circunstancias en las que se encontraba José Manuel, construcción literaria; se conformabaa las circunstancias verdaderas de muchos músicos afrolatinos en el siglo XIX y entrado el XX (Nodal 158). ${ }^{14}$

Por eso, en la payada que nos crea López Albújar, el protagonista abandona el modo musical europeo que había formado parte del discurso de enajenamiento que le había impuesto la sociedad esclavista para acudir a una expresión más profunda y significativa. José Manuel convierte el foro público del día de Corpus Christi en un espacio de rito transformativo, e "induce un movimiento del espíritu mediante los efectos de la melodía y

\footnotetext{
${ }^{13}$ Ciertos detalles de su atavío en la escena de la payada refuerzan su imagen romántica - las sandalias o cotornos, calzado típico de los actores de dramas y tragedias en el teatro griego clásico; su camisa con las mangas y cuello byronescos (López Albújar 162).

${ }^{14}$ Como otro ejemplo de esto, véase en Cecilia Valdés de Cirilo Villaverde, la vida del sastre-músico, el mulato Pimienta.
} 
el ritmo [...]" (Wilson 98). Al leer en una discusión sobre la santería que "los yoruba expresan la presencia del ashé (el poder, la fuerza, la energía) de los orixás en la complejidad y los matices rítmicos" (Murphy 27), se encuentran varias resonancias en la representación de la payada y el modo que en López Albújar lo emplea como recurso literario. José Manuel mismo viene a ser emblema de la colectividad de los esclavizados. Dadas las circunstancias históricas y económicas tratadas en la novela, la música de José Manuel, por necesidad, plantea un nuevo orden. En él tanto se reconstituirían las estructuras económicas como se modificaría la consciencia de la gente.

En cuanto al cambio que puede resultar como consecuencia del drama social, Turner plantea una urgencia, un desafío a las presuposiciones y percepciones en vigencia, un momento cuando una nueva relación se hace obligatoria por la fuerza (78-79). Yo quisiera sugerir que en el caso de la payada la urgencia del drama social de que habla Turner nace como una reacción a una amenaza. Lo es más que nada por los principales que observan el espectáculo. En cambio, para los participantes, viene a ser una manera de tomar y tener el poder, al menos por lo que dure el evento.

Tal como se presenta en esta novela, la payada es rito. "El rito", dice Turner, "es un proceso generativo y re-generativo" (86). Esto describe la esencia de la payada elaborada por López Albújar. El que gana la payada lo hace precisamanete por la transcendencia de su estilo de tocar. Se trata de un público que hasta ese momento lo había menospreciado y denigrado. Es la manifestación del espíritu, esa descarga, ese ponerse de manos, que ocurrió entre el músico y su público en el momento de éxtasis, de mayor acercamiento. En aquel momento de la payada la propia reacción de ese público remonta más allá de él mismo.

El propósito de un nuevo orden que forma parte del texto se ve reforzado por ciertos detalles tales como el significado del día escogido para la payada. La fiesta de Corpus Christi celebra el descenso del Espíritu Santo sobre los discípulos de Cristo. Según la descripción de la Biblia, a este acto lo acompaña un gran ruido, a causa del cual todos se verán cambiados. ${ }^{15} \mathrm{Al}$ enfocarse en el descenso del Espíritu Santo el lector se enfrenta con las cuestiones de la percepción, la transformación, la autorización del individuo y de la proclamación. Matalaché se desarrolla por medio de las alteraciones de sus personajes, José Manuel, más que ninguno. El episodio de la payada según lo construye López Albújar es el evento culiminante de revelaciones y transformaciones, sobretodo si se tiene en mente el papel que los estereotipos de los negros y los mulatos han tenido en la novela. La posibilidad de realizar estas transformaciones se intensifica al incorporarse a los propósitos de la fiesta de Corpus Christi. Según Fernando Ortiz, esta fiesta de después de Pascuas tiene varios elementos en común con las del Día de Reyes y el Carnaval: la participación de los bailadores, tamboreros, procesiones, sobre todo los disfrazados que se llaman "diablitos"

\footnotetext{
${ }^{15}$ La Biblia Hechos II, vv $14-16,19$, nos dice que "[A]l cumplirse el día de Pentecostés, estando todos juntos en un lugar, se produjo de repente un ruido proveniente del cielo como el de un viento que sopla impetuosamente, que invadió toda la casa en que residían. Aparecieron, como divididas, lenguas de fuego, que se posaron sobre cada uno de ellos, quedando todos llenos del Espíritu Santo; [...] ." Y allí mismo explica como Pedro [les habló] a los varones judíos, diciéndoles: "apercibíos y prestad oídos a mis palabras [...] esto es lo dicho por el profeta Joel: 'y sucederá en los últimos días, dice Dios, que derramaré mi Espíritu sobre toda carne, $[\ldots]$ y haré pródigos arriba en el cielo y señales abajo en la tierra [...]'." (El énfasis es mío).
} 
(Brea, citando a Ortiz 115). Sabidos son los propósitos del carnaval. Bettelheim con muchos otros refiere al carnaval como "a deliberate moral cleansing, [una purga moral deliberada]." También menciona una actividad parecida en Guinea, cuyo propósito es el explusar de los espíritus malignos y el permitir la invectiva contra los de posición social superior" (33).

Las varias referencias al ritmo/baile "diablo", "diablito", resultan ser un motivo ricamente evocador si se toma en cuenta y se relaciona con la observación siguiente: cuando se pierde el idioma africano, como en el caso de las culturas de la diáspora, muchas veces se recurre al baile como expresión mimética de las palabras perdidas de cantos y conjuros (Drewal 228). De ahí, tal vez, la importancia de la figura del "diablo" en la literatura de la música y del baile de la diáspora. Ortiz, en Bailes, menciona varios bailes/ritmos, como por ejemplo, La Kulona (129), que en menor grado es el de los diablillos. Otro ejemplo del parecido entre los bailes y ritmos llamados "diablos" es el íreme (465), descrito como el baile con los muertos aparecidos —o sea, una invocación a los ancestros, el baile de los ñánigos, (hombres iniciados en sociedades de secretos, dotado de poderes especiales y cargados de obligaciones correspondientes). Hay ciertos movimientos asociados con los diablitos que en la descripción de la payada hacen un papel importante como se verá más adelante. Al hablar de la función de estos bailes como manifestaciones de la africanía, Ortiz insiste en que "[...] los bailes de Ogún, de los íreme, y demás aparecidos, realizan la función religiosa y social de mantener el temor al misterio como descarga catártica de las tensiones psíquicas y como medio de asegurar las sanciones establizadoras y cohesivas del régimen tribal en todas las clases, sin distinción de rangos" (Bailes 483). Si se sustituye "socio-político" por "tribal" se ve como esta función corresponde a la que José Manuel emprende cuando él entra en la payada. El aprovecha de lo que le ofrece la payada a él; sigue fiel a sus propias motivaciones, no comprometido con las de los amos. Por ser la payada un sistema de códigos polivalentes, los amos no estarían enterados.

Volvamos a las formas encerradas de transmitir el conocimiento, sea por la descripción de los bailes, por los mismos movimientos, sea por la música. Ya se ha documentado que los ritmos y hasta la fraseología de la música afrocubana se derivan de la música ritual africana veces encerrada en la secular. ${ }^{16}$ La tendencia de poner en clave cierta información o la difusión de ciertos elementos culturales se confirma también al recordar que Ortiz, en 1947, había tendio noticias de un pueblo (venezolano) en el cual "en realidad los diablitos del Corpus Christi representaban una cabal reproducción del íreme afrocubano". ${ }^{17}$ Así la tendencia de recurrir a las estrategias de proteción que recurren a lo clandestino, lo disfrazado, al encierre de los signos para que sólo los iniciados los percibieran.

Hay más que el día y los bailes que contribuyen al complejo de signos en clave que se plantea en este trabajo. López Albújar evoca las procesiones mismas de las fiestas en su

\footnotetext{
${ }^{16}$ Ortiz, Africanía 327-328, por ejemplo, da el caso de una canción recogida en 1938 en Tennessee del oeste. Tenía una melodía parecida a otra encontrada en Inglaterra, Portugal, Brasil, Cuba, y las Antillas británicas que resultó ser un canto de los cultos de Shangó, orishá yoruba. Era una invocación a la divinidad para la protección del niño. En su manifestación cubana, la canción/conjuro/invocación venía intercalada en una canción de cuna. Luego la escribió Gilberto Vaz, compositor de sones. ${ }^{17}$ Ortiz, Bailes 465, citando a Sojo 1947, 10. Tal Sojo será seguramente el escritor y antropólogo afrovenezolano Juan Pablo Sojo entre cuyas obras figuran Temas y apuntes afro-venezolanos, Caracas, 1941 y Las cofradías etno-africanas en Venezuela, 1947.
} 
descripción de los dos esclavos cumaneros al entrar ellos a tocar la payada. Por ejemplo, los trajes: el del Nicanor, descrito como traje criollo de liberto, con un machete enorme que lleva bien como parte de lo criollo o bien como modo de identificarlo como devoto al orishá Ogún, quien, además de las ya mencionadas cualidades, exige sacrificios. Examinada a lo largo de la payada su comportamiento, su manera de tocar - caracterizada por un frenesí desencadenado - todo cuanto conduzca al momento de la derrota de Nicanor por José Manuel admite esta interpretación. De él vino el reto de que quien perdiera la contienda, perdiera la mano $(170)^{18}$ y cuando le tocó cumplir, lo hizo en el estilo de los movimientos atribuídos a Ogún. En el caso de José Manuel el jubón de piel de tigre con la camisa byroniana anteriormente discutidos sirve de otro ejemplo de signos en clave (168).

Merece nuestra atención también la manera en que López Albújar utiliza y maneja ciertos colores. A los orishás se les asocian colores y atributos; ritmos, movimientos y gestos específicos. Se les conceden preferencias en lo relativo a fragancias, comidas, bebidas, y animales. Resulta que el rojo es el color de Ogún (T. Barnes 176). El orishá Shangó, cuyo color es el azul —el color que también indica el itutu, con sus atributos del trueno, el relámpago, y la capacidad de aliviar y sanar-cuyo elemento es la madera, es el orishá que a menudo se encuentra en conflicto con Ogún. Bettelheim, al discutir el carnaval en Santiago de Cuba, observa que tanto la regalía del cabildo y sus banderetes de identificación como ciertos instrumentos musicales públicamente anuncian la capacidad del cabildo de comentar y criticar la sociedad y hasta de hacer un papel activista en ella. En un espectáculo público, la autoridad del cabildo se mostró en términos visuales, ortorgándole así a la actividad ritual una actualidad estética y social, comprensible para aquellos que pudieran descifrar el lenguaje del espectáculo" (Bettelheim 142). En la payada de López Albújar éstos corresponden al público de esclavos y libertos negros y mulatos que presencia la payada.

Al entrar José Manuel en la payada, López Albújar dirige la atención del lector a su guitarra "[...] de cuyo clavijero pendía un manojo de cintas rojas y azules [...]" (169). Estas se pueden interpretar como miniaturas de los banderetes y la regalía que por lo general acompañaba a los músicos y los disfrazados durantes los festivales de Corpus Christi (Nodal 163). Tanto esta miniaturización como la criollización de ciertas actividades relacionadas con los tambores pueden representar tácticas protectoras (Nodal 160).

Más información se adquiere sobre las interpretaciones posibles de las cintas al determinar patrones de posición y función. Los colores en el contexto de las fiestas de la diáspora frecuentemente tienen un uso oposicional y dialéctico. Por ejemplo, Bettelheim documenta unas celebraciones de Jamaica de fin del año un momento cargado de significación y potencialidades, igual al trasfondo histórico de la novela y más especificamente, la payada del día de Corpus Christi. Se cita la coincidencia de las dos fiestas - la del Año Nuevo y la del Día de Reyes - con sus conotaciones de ser "una deliberada limpieza o purga moral" y "una ocasión en la que se permite la invectiva en contra de los de clase social superior" (Bettelheim 23). El ejemplo de Jamaica que ofrece Bettelheim asocia a "Juan Canoa [John Canoe, o Juncanoo] con las banderas rojas y Juan Langostino [John Crayfish] con las banderas azules. Ortiz hizo también una referencia a tal dicotomía de colores como algo que

${ }^{18}$ Bettelheim, escribe cómo Ogún ataca los presentes con su machete y luego se ataca a sí mismo (158); correspondiendo esto a la configuración de acciones al final de la payada. 
todavía "mantenía su vigencia en varias fiestas en Cuba" (Bettelheim 36). Brea y Millet escriben acerca de una ceremonia de banderetes con la participación de dos cofradías, las comparsa "la ceiba de plata" y "la espina de oro" con sus colores distintivos, el azul y el rojo respectivamente (Bettelheim 111).

Hasta el momento de la payada el azul y el rojo habían funcionado dialécticamente: aquél, connotador de la herencia europea, de la civilización; éste, connotador de la herencia africana, identificado como la barbarie. Sin embargo en la payada aparecen juntos y en una función ritual. Teniendo en cuenta el concepto tan estimado de la cultura yoruba - la dualidad y el doble - se admite la posibilidad de otras fusiones hasta en la creación de los personajes. Si la examinamos desde esta perspectiva la construcción de José Manuel parece haberse hecho por una combinación de las características de los orishás Ogún y Shangó. Nicanor, el esclavo negro puro, criollo, se convierte en otro aspecto del ser de José Manuel, lo cual hace que en la payada José Manuel se oponga a sí mismo. Por la manera de vestirse Nicanor — con traje de liberto, también por la compleja relación con su amo de hombre privelegiado aunque esclavizado se asocia el adversario de José Manuel con la vida éste en su época anterior a la llega a La Tina. En aquel entonces José Manuel era el hijo natural consentido que gozaba de los privelegios de liberto y hasta de los de un hijo del amo. El momento histórico de este breve idilio hubiera sido cuando la sociedad esclavista se encontraba en auge y bastante más segura de poder mantener su hegemonía. También hubiera sido un periódo formativo de la consciencia de una identidad racial-cultural, pero uno en la cual el protagonista se percibía más vinculado con la vida y sociedad del amo que con los esclavos a la vez que se adquiera los conocimientos que serían su formación en la cultura africanaperuana. Así se funde la historia personal con la historia regional.

Se puede entender a José Manuel como personaje metonímico--in locus ñánigo-por el papel ritual y social que éstos ejercían. Ya se ha comentado la fuerte presencia de los bailes/ritmos llamados “diablos" en la presentación de José Manuel, y la probabilidad de que sus variantes aparecieran con otro nombre. ${ }^{19}$ Ortiz describe su esencia con una cita de los ñáñigos mismos cuyo baile es: "la boca del diablito está en sus manos y en sus pies" (Bailes 471). En Matalaché, los dones y los poderes que posee José Manuel se manifiestan más que nada en sus manos; y desde luego es el caso al ver su actuación en la payada. Si aceptamos la creación literaria de López Albújar como tal personaje, podemos valernos de José Manuel como representante de todos los danzantes y músicos de las cofradías y comparsas que se encargarían de los propósitos y las posibilidades expresivas de la ocasión: la afirmación cultural, la crítica social, la propuesta de un nuevo tipo de orden. Recordemos la autoridad del cabildo investida en ellas en las ocasiones significativas.

Si bien la música de José Manuel evoca en clave lo terrible de la trata de negros, también proclama un fuerza que resiste aquella enorme opresión. Se aprecia la actuación de José Manuel durante la payada y es privilegiada en gran parte a causa de la síntesis y la composición que revela. El busca nuevas formas de comunicación. En cuanto a la composición, Attali dice, "[S]i componemos música, somos constantemente formados por la historia, por las situaciones que siempre nos están cambiando. En la composición,

\footnotetext{
${ }^{19}$ David H. Brown, "An Annotated Glossary to Fernando Ortiz' 'The AfroCuban Festival Day of the Kings' en Bettelheim, Cuban Festivals, 90. Brown cita a Odilio Urfé, "Music andDance in Cuba", en Africa en Latin America: Essays in History, Culture and Sociology (176).
} 
producir es ante todo complacerse con la producción de diferencias, del redescubrimiento y el florecimiento del cuerpo [...] la conecta a los ruidos de la vida y del cuerpo, cuyo movimiento se aprovisiona. Está cargada con el riesgo perturbador; es un reto inestable, un festival anárquico y ominoso, como un Carnaval con un resultado imprevisible [...] Componer es así simultáneamente matar y ejecutar un sacrificio" (Attali 141).

La composición musical original de José Manuel es un aspecto de la payada que nos permite hablar del "asesinato" a nivel conceptual. Nos referimos al de la imagen estereotipada creada e impuesta al mulato por los amos de esclavos. El asesinato se logra a nivel literal de la narrativa a través de un acto, en la conclusión de la payada, que se puede leer como un sacrificio. El negro Nicanor, perdido el mote de "Mano de Plata", por haber perdido la contienda a José Manuel cumple con la palabra del reto que se había lanzado al comienzo de la payada con movimientos característicos tipo Ogún: "[...] con feroz resolución se le amputó de un tajo" (177). No sucede así sólo por la vanidad de Nicanor. Este sacrificio adquiere nuevas dimensiones si lo entendemos en el contexto informado por los orishás. Al discutir los aspectos del drama social, Turner escribe que "el desmembrar bien puede ser preludio al remembrar" o sea reintegrar los elementos fragmentados de la sociedad (86). Lo que exige el sacrificio de la mano, más allá que la honra de Nicanor para cumplir con su palabra, es la autoridad de José Manuel que le es conferida por la intensidad de su música y su modo de tocar que nace de su modo de ser y de estar. Se refiere al poder innato, además de a su estado alterado, que se aumenta con cada frase musical. En la novela de López Albújar, la pérdida de la mano del esclavo negro es el acto de desmembramiento que sirve de preludio al reconocimiento del ser que él con José Manuel representa. Es un dirigirse hacia aquellos tiempos antes de la violación y la fragmentación del pueblo africano por la esclavitud. El sacrificio que da remate al episodio de la payada puede leerse como una ofrenda para que el intercambio entre el mulato y su público se acepte y se consolide; es éste el nuevo orden que la música plantea.

Al hacerse apreciar "de un golpe [como el] guitarrista, el repentista, [e]l cantor y [e]l hombre" por su público, aquel día de Corpus Christi, José Manuel se expuso al riesgo de dejarse conocer (173). Con esto se anticipa que se haga pública su relación con María Luz y las inevitables consecuencias que le esperan. Para José Manuel, el sacrificio supremo será la muerte en una tina de hierro de sebo hirviente. Precede su muerte la escena de confrontación entre él y don Francisco, el padre de María. En esa ocasión muestra el mulato el máximo control de sus emociones. La supremacía de su autoridad relumbra en sus últimas palabras: “¿Quién es la bestia, usted o yo?” (194).

Es la payada elaborada por López Albújar la que nos ha conducido hasta este punto y su insistencia en aprovecharse de la forma y la intención de los ritmos y bailes como los diablitos, los íreme y las musicalidades originales y provocadoras. Los aspectos bien tradicionales de la música cubana, aunque algo exótico en el contexto piurano, sobre todo lo de "los movimientos inusitados adredes" según los describe Ortiz (Bailes 473) aparecen reflejados en el conjunto de detalles musicales de la payada. De los diablitos, el deseo de impresionar y aterrorizar a los espectadores coincide con los propósitos del protagonista, aunque hay que calificar el proceso de aterrorizar en este caso. Al considerar el conjunto de las maneras de tocar de ambos cumananeros: la del negro Nicanor, su música, lo consabido, bien tocado, pero de un modo desenfrenado; la del mulato José Manuel, 
profundamente conmoverdora aunque carecente del frenesí, puesto que ese aspecto le es dictado por el itutu. Vale decir que en cuanto a la reacción del público lo que unos entienden como aterrorizar - las evocaciones sutiles y disfrazadas de las comparsas y sus bailes presentes en la música de José Manuel - otros lo pueden entender por conjuro y esfuerzos por atraer al espíritu. Así que los movimientos, especialmente los de Nicanor, durante la payada evocan los atributos de Ogún, divinidad además de lo ya citado, del crucecaminos, ese lugar liminal, abierto al cambio, y a la transformación.

Aquellas expresiones y revelaciones de poder que "impresionan y aterrorizan", si se consideran las implicaciones de tal reformulación de la identidad que José Manuel mismo emprende en el momento de la payada no sólo plantean el honor y el respeto por su humanidad como fundamentales, sino que su ser, su comportamiento, sus creaciones musicales se los exige de su público. La payada se entiende como rito cuya función es, según Turner, la de sanar y restaurar el grupo social dañado por los males - en este caso, los de la esclavitud. Esto se adecua con lo que Ortiz nos explica (Bailes 483).

Si se entiende al negro Nicanor como un aspecto del mulato José Manuel, el sacrificio a la conclusión de la payada se convierte en un sacrificio para José Manuel también. Es un sacrificio precipitado por los orishás como parte de un evento, diríamos rito, que conduce a un (re)nacimiento. No tanto para José Manuel sino para aquellos criollos blancos que habían escuchado su música. Para él, sobre todo tomando en cuenta los detalles de la africanía en clave y disfrazados en el texto que se ha explorado aquí, se trata aún más de una afirmación. La declaración implícita de que es hombre libre capacitado para todo era una afirmación radical que amenazaba profundamente la autoridad y el orden coloniales, aún más estando en vísperas de cambios. La fuerza de las creaciones musicales sitúan a José Manuel en una posición limítrofe entre el viejo mundo de la esclavitud y el nuevo mundo anticipado por la abolición de la esclavitud y la implementación de la independencia.

El nuevo orden, nacido de un discurso de diferencia, fundida en la africanía, que anuncia López Albújar a través de su protagonista tiene el fin de remediar y sanar. Quien se encarga de imponerlo es la figura más alejada posible del esclavo -el mulato José Manuel, quien logra mediante la payada, presentarse como hombre libre que se mueve dentro de un orden social transformado que lo acepte y lo aprecie. También como hombre libre consciente de ciertos ritos culturales traídos de Africa. Que esto se logre a nivel narrativo solamente por la duración de la payada como rito, como drama social, es otra historia y otro trabajo. Esta relectura de la novela de López Albújar procura colocarla en un continuum que según se imagina es formado en la época colonial con la llegada de los esclavos que llegaban a los puertos de su nuevo destino en el Caribe y las Américas. Al establecerse en la hacienda, la Casa grande o en los campos, habrían aprovechado de sus conocimientos de ciertos ritos, tradiciones, festivales, igual que de ciertos estilos y ritmos musicales. No digamos de preparaciones de la comida, decoraciones y adornos, o el modo de atar un corte de tela. Todo contendría la posibilidad de servirles de clave. Quisiera plantear la posibilidad de que un autor de origen afroperuano, nacido y criado y formado en el siglo XIX, en vísperas del XX, escribiera en el mismo espíritu de poner en clave cierta información en ésta, su única novela que explícitamente trata de temas raciales. López Albújar, escritor tal vez más enterado del "folklore" de la africanía en el Perú y de las conexiones diaspóricas de lo que se ha creído, incorpora algo de este material en el texto; 
explorando y explotando a través de la diferencia las convergencias culturales de significado. La postulación radical tan válida de López Albújar no se cumplió ni en la cronología narrativa de su novela, ni en la época de escribirla y publicarla, y en la actualidad aún está por realizarse de verdad.

\section{BiBLIOGRAFIA}

Ajuwon, Bade. "Ogún's Iremokje: A Philosophy of Living and Dying” . Africa's Ogún. Sandra T. Barnes, ed. Bloomington: IndianaUniversity Press, 1989. 173-198.

Andrews, George Reid. The Afro-Argentines of Buenos Aires. Madison:University of Wisconsin Press, 1980.

Attali, Jacques. Noise, The Political Economy of Music [Bruits: Essai sur l'economie politique de la musique], 1977 [Presses Universitaires de France] Brian Assum, trad. Minneapolis:University of Minnesota Press, 1985.

Bettelheim, Judith. Cuban Festivals: An Illustrated Anthology. Nueva York/Londres: Gardners, 1993.

Blanchard, Peter. Slavery and Abolition in Early Republican Peru. Wilmington, DE: Scholarly Resources, Inc., 1992.

Bowser, Frederick P. The African Slave in Colonial Peru; 1524 -1650. Palo Alto, CA: Stanford University Press, 1974.

Brea, Rafael y José Millet. "Glossary of Popular Festivals". Cuban Festivals: An Illustrated Anthology. Judith Bettelheim, ed. Nueva York/Londres: Gardners, 1993. 99-137.

Brown, David H. "An Annotated Glossary to Fernando Ortiz' 'The AfroCuban Festival Day of the Kings"'. Cuban Festivals: An Illustrated Anthology. Judith Bettelheim, ed. Nueva York/Londres: Gardners, 1993. 49-98.

Chandler, David C. "Slave Trade of New Granada". Slavery and Race Relations in Latin America. Robert Brent Toplin, ed. Westport,CT: Greenwood Press, 1975.

Dobard, Raymond G. y Jacqueline L. Tobin. Hidden in PlainView: The Secret Story of Quilts and the UndergroundRail Road. Nueva York: Doubleday, 1998.

Escajadillo, Tomás G. “Análisis de Matalaché, Paraleer a Matalaché: el mundo polivalente de una novela retaguardista". La narrativa de López Albújar. Lima: Ediciones CONUP, 1972. 171-328.

Gates, Henry Louis, Jr. (ed.). "La narrativa de la vida de Frederick Douglass". The Classic Slave Narratives. Nueva York: Mentor 1987. 30-31.

Lockhart, James. Spanish Peru, 1532 - 1560: A Colonial Society. Madison, WI: University of Wisconsin Press, 1968.

López Albújar, Enrique. Matalaché; una novela retaguardista. $3^{\text {a }}$ ed. Lima: Ediciones Populares, Juan Mejía Baca y P.I. Villanueva, 1957.

MacCaffey, Wyatt. Astonishment and Power. Washington, DC: The Smithsonian, 1996.

Markham, Robert Clement. A History of Peru. [c1892]. Nueva York: Greenwood Press, 1968.

Mellafe, Rolando. Negro Slavery in Latin America. JWS Judge, trad. Berkeley:University of California Press, 1975. 
Mörner, Magnus. Race Mixture In Latin America. Nueva York: Columbia University Press, 1965.

Murphy, Joseph M. Santeria: African Spirits in America. Boston: Beacon Press, 1988.

Nicholls, Andrea. Notes for the Loango Tusk [Notas del colmillo de Loango]. Washington, DC: The Smithsonian, 1997.

Nodal, Roberto. "The Social Evolution of the Afro-Cuban Drum". The Black Perspective in Music II (Fall 1983): 157-177.

Ortiz, Fernando. Los instrumentos en la música afrocubana. La Habana:Editorial de Ciencias Políticas, 1952.

Nuevo Catauro de Cubanismos. La Habana: Dirección cultural del Ministerio de Educación, 1974.

Sarmiento, Domingo Faustino. Civilización y barbarie o la vida de don Facundo Quiroga. Antología de la Literatura latinoamericana. Enrique Anderson Imbert y Eugenio Florit, eds. Nueva York: Holt, Rinehart and Winston, 1960.

Scott, James C. Weapons of the Weak: Everyday Forms of Peasant Resistance. New Haven: Yale University Press, 1985.

Sojo, Juan Pablo. Temas y apuntes afro-venezolanos, Caracas, 1941 y Las cofradias etnoafricanas en Venezuela, Caracas: Cultura Universitaria, 1947.

Steptoe, Robert J. From Behind the Veil: A Study of Afro-American Narrative. Urbana/ Chicago/Londres:University of Illinois Press, 1979.

Turner, Victor. From Ritual to Theatre: The Human Seriousness of Play. Nueva York: The Peforming Arts Journal Publications, 1974.

Thompson Drewal, Margaret. "Dancing for Ogún in Yorubaland and Brazil". Africa's Ogun: Old World and New. Sandra T. Barnes, ed. Bloomington: University of Indiana Press, 1989. 199-234.

Thompson, Robert Farris. African and African American Art and Philosophy. Nueva York: Ranfom House, 1982.

Urfé, Odilio. "Music and Dance in Cuba". Africa in Latin America: Essays in History, Culture and Sociology. Mario Moreno Fraginals, ed. Nueva York/París: Holmes \& Meier, 1984. 170-188.

Villaverde, Cirilo. Cecilia Valdés, o La loma del Ángel. México: Ediciones Porrúa, 1976. Wilson, Sule Greg. the Drummer's Path; Moving the Spirits with Ritual and Traditional Drumming. Rochester, VT: Destiny, 1998. 